\title{
PERAN CORPORATE GOVERNANCE DALAM MENURUNKAN KEBANGKRUTAN PADA PERUSAHAAN DI INDONESIA
}

\author{
Tasya Hilaliya dan Farah Margaretha \\ Fakultas Ekonomi dan Bisnis Universitas Tri Sakti \\ Email: farahmargaretha@gmail.com
}

\begin{abstract}
This research examines the influence of Corporate Governance on Firm Performance measured by Tobin's Q and Financial Distress measured by Z-score. The samples used were 72 companies engaged in the manufacturing industry are listed on the Indonesia Stock Exchange (BEI) for five years from 2011 to 2015. The analytical methods used in this research is panel data regression, discriminant analysis, and logistic regression. The results showed that (1) there is no significant impact between corporate governance practices on firm performance. (2) there is negative impact between corporate governance practices on financial distress. Then, the companies need to increase corporate governance in order to avoid possibility of financial distress and for the investor before making an investment should consider the factors that affect the firm performance and financial distress.
\end{abstract}

Keywords: Corporate Governance, Financial Distress, Firm Performance.

Abstrak: Jika Perusahaan dapat melaksanakan praktek yang baik, maka dapat melindungi perusahaan terhadap resiko kebangkrutan. Penelitian ini menguji pengaruh Corporate Governance terhadap Kinerja Perusahaan yang diukur oleh Tobin's Q dan Kesulitan Keuanagan yang diukur oleh Z-score. Sampel yang digunakan sebanyak 72 perusahaan yang bergerak dalam industri manufaktur yang tercatat di Bursa Efek Indonesia (BEI) selama lima tahun dari 2011-2015. Metode analisis yang digunakan dalam penelitian ini adalah analisis data panel, analisis diskriminan, dan regresi logistik. Hasil dari penelitian ini adalah (1) Pelaksanaan Corporate Governance tidak berpengaruh terhadap Kinerja Perusahaan. (2) Pelaksanaan Corporate Governance berpengaruh negatif terhadap kemungkinan Kesulitan Keuangan. Maka dengan itu, perusahaan harus meningkatkan pelaksanaan corporate governance agar terhindar dari kemungkinan kesulitan keuangan dan bagi investor sebelum melakukan investasi sebaiknya memperhatikan faktor-faktor yang mempengaruhi kinerja perusahaan dan kesulitan keuangan.

Kata kunci: Corporate Governance, Kesulitan Keuangan, Kinerja Perusahaan.

\section{PENDAHULUAN}

Krisis ekonomi di Asia yang terjadi tahun 1997 berimbas pada perekonomian Indonesia. Setelah krisis tersebut melanda, isu mengenai praktek corporate governance mulai berkembang, khususnya pada saat Indonesia mengalami krisis yang berkepanjangan pada tahun 1998. Selain itu, pada tahun 1999 negara-negara lain yang terkena dampak dari krisis tersebut perekonomiannya sudah mulai pulih, kecuali Indonesia. Hal ini menjadi perhatian pemerintah dan fokus utama para pelaku usaha dalam mengelola usahanya demi keberlangsungan perusahaannya. Banyak pihak yang berpendapat bahwa 
lambatnya pemulihan di Indonesia terjadi karena lemahnya praktek corporate governance yang di terapkan di perusahaan-perusahaan (Wardhani, 2007).

Kinerja merupakan proses dimana organisasi mengelola kinerjanya untuk mencocokkan strategi korporasi dan strategi fungsional dalam mewujudkan tujuan perusahaan (Al-Matari et al. 2014). Setiap perusahaan pasti mempunyai tujuan jangka pendek yaitu untuk menghasilkan laba dan tujuan panjang yaitu meningkatkan nilai perusahaan, termasuk untuk perusahaan yang bergerak dalam industri manufaktur. Di tengah persaingan yang begitu ketat pada industri manufaktur maka industri ini akan lebih rentan untuk mengalami kesulitan keuangan apabila manajemen tidak mengelolanya dengan baik. Penerapan corporate governance yang baik adalah salah satu faktor yang dapat mempengaruhi kinerja perusahaan.

Jensen dan Meckling (1976). agency theory yang menekankan pentingnya pemilik perusahaan (principal) menyerahkan pengelolaan perusahaan kepada professional (agent) yang lebih mengerti dan memahami cara untuk menjalankan suatu usaha. Jensen dan Meckling (1976). berpendapat bahwa keberadaan masalah principal-agent sebagai konsekuensi dari pemisahan kepemilikan dan kontrol menimbulkan konflik antara kepentingan manajer dan pemegang saham. Maka manajer pada akhirnya akan memiliki hak pengendalian dalam hal bagaimana mereka mengalokasikan dana investor (Jensen dan Meckling 1976). Satu kesalahan yang dilakukan dalam pengambilan keputusan dapat mengakibatkan kerugian besar bagi perusahaan yang dapat berakhir pada financial distress (Cinantya dan Merkusiwati, 2015).

Financial distress merupakan keadaan dimana kondisi keuangan perusahaan terus menurun setiap tahunnya. Apabila keadaan perusahaan yang sudah mendekati financial distress biasanya manajemen perusahaan mengambil keputusan untuk menutup semua kegiatan dalam perusahaaan baik itu kegiatan produksi maupun kegiatan operasional lainnya sebelum terjadi kebangkrutan atau yang sering disebut likuidasi (Widyasaputri, 2012). Menurut Parker et al, (2002) dan Abdullah, (2006), Jika perusahaan dapat melaksanakan praktek-praktek corporate governance maka dapat melindungi perusahaan terhadap risiko financial distress.Penelitian ini bertujuan (1) menganalisis pengaruh pelaksanaan corporate governance terhadap kinerja perusahaan.dan (2) menganalisis pengaruh pelaksanaan corporate governance terhadap kemungkinan financial distress.

\section{TINJAUAN PUSTAKA}

Financial Distress. Financial distress atau kesulitan keuangan, terjadi sebelum suatu perusahaan benar-benar mengalami kebangkrutan. Menurut Beaver et aI, (2010) Financial distress didefinisikan ketidakmampuan perusahaan untuk membayar kewajiban financial yang telah jatuh tempo. Financial distress dapat diukur menggunakan metode yang dikemukakan oleh Edward Altman yang disebut dengan Altman Z-Score (1968). Menurut Hussain et al. (2014), Z-score merupakan metode yang cukup akurat untuk memprediksi financial distress dan sangat berguna untuk manajer, investor, dan stakeholder. Beberapa kriteria yang mengindikasikan bahwa perusahaan yang masuk dalam kategori financial distress, yaitu Darmawan (2016), mengkategorikan perusahaan mengalami financial distress apabila mempunyai earning per share (EPS) negatif. Sedangkan Wardhani (2007), menyatakan bahwa perusahaan yang sedang mengalami financial distress apabila memiliki interest coverage ratio (ICR) kurang dari satu dan menurut Khaliq et al. (2014), 
Kriteria untuk perusahaan yang mengalami financial distress kriterianya adalah yang mempunyai current ratio $<1.1$.

Kinerja Perusahaan. Kinerja merupakan proses dimana organisasi mengelola kinerjanya untuk mencocokkan strategi korporasi dan strategi fungsional dalam mewujudkan tujuan perusahaan (Al-Matari et al. 2014). Setiap perusahaan pasti mempunyai tujuan jangka pendek yaitu untuk menghasilkan laba dan tujuan panjang yaitu meningkatkan nilai perusahaan. Penilaian terhadap kinerja dilakukan untuk memotivasi karyawan dalam mencapai sasaran organisasi yang telah ditetapkan sebelumnya agar dapat membedakan hasil dan tindakan yang diinginkan.

Corporate Governance. Good corporate governance menurut komite Cadbury (1992), merupakan sistem yang mengarahkan dan mengendalikan perusahaan dengan tujuan agar tercipta keseimbangan antara perusahaan dengan stakeholder. Perusahaan perlu menerapkan good corporate governance untuk memberikan kemajuan terhadap kinerja suatu perusahaan dan menjadikan perusahaan dapat terus beroperasi dan dapat dipercaya. Menurut Gitman dan Zutter (2015), corporate governance mengacu pada aturan, proses, dan hukum-hukum yang perusahaan operasikan, perusahaan kontrol dan perusahaan atur. Ini mendefinisikan hak dan tanggung jawab peserta perusahaan seperti pemegang saham, dewan direksi, manajer, dan pemangku kepentingan lainnya, serta aturan dan prosedur untuk membuat keputusan perusahaan. Menurut Klapper dan Love (2002), terdapat hubungan positif yang signifikan dari corporate governance terhadap kinerja perusahaan. Windah dan Andono (2013), menyatakan bahwa tidak adanya pengaruh antara penerapan corporate governance terhadap kinerja perusahaan.

Leverage. Leverage merupakan rasio yang menghitung seberapa jauh dana yang disebabkan oleh kreditur, juga sebagai rasio yang membandingkan total utang terhadap keseluruhan aktiva suatu perusahaan, maka apabila investor melihat sebuah perusahaan dengan aset yang tinggi namun resiko leveragenya juga tinggi, maka investor akan mempertimbangkan kembali untuk berinvestasi pada perusahaan tersebut. Menurut Shahwan (2015), leverage positif mempengaruhi kinerja perusahaan. Syari (2014), menyatakan tidak terdapat pengaruh antara leverage terhadap kinerja perusahaan. Parker et al. (2002), menemukan bahwa leverage secara negatif berhubungan dengan financial distress.

Current Ratio. Talebria et al. (2010), mengatakan bahwa current ratio didefinisikan sebagai current asset dibagi dengan current liabilities. Hasil dari current ratio yang menunjukkan hubungan positif terhadap financial distress adalah harapan perusahaan, karena rasio likuiditas yang tinggi menunjukan bahwa keuangan perusahaan baik. Menurut penelitian Yuniarta et al. (2015), ditemukan tidak adanya pengaruh antara current ratio terhadap kinerja perusahaan. Shahwan (2015), current ratio memiliki pengaruh negatif signifikan terhadap financial distress. Putri dan Merkusiwati (2014), menemukan bahwa tidak terdapat pengaruh yang signifikan antara current ratio terhadap kondisi financial distress.

Book to Market Ratio. Book to market ratio merupakan rasio nilai buku ekuitas terhadap nilai pasar ekuitas yang juga digunakan sebagai indikator persepsi risiko pasar perusahaan. Vassalou dan Xing (2004), mengatakan bahwa dan semakin tinggi book to market ratio 
maka kemungkinan kebangkrutan akan semakin tinggi. Menurut penelitian yang dilakukan di Egypt oleh Shahwan (2015), menemukan bahwa book to market ratio tidak memiliki pengaruh terhadap financial distress, sedangkan pengaruh antara book to market ratio memiliki pengaruh negatif signifikan terhadap kinerja perusahaan.

Return On Sales. Rasio ini digunakan untuk mengukur kemampuan suatu perusahaan dalam menghasilkan keuntungan (Gitman dan Zutter, 2015). Apabila ROS yang diperoleh tinggi maka menunjukkan semakin besar fluktuasi kemampuan manajemen dalam menghasilkan laba operasi. Hal ini dapat mempengaruhi investor dalam memprediksi laba dan memprediksi kelangsungan perusahaan dalam menjalankan usahanya sehingga memberikan dampak pada kepercayaan investor terhadap perusahaan. Pada penelitiannya Cinantya (2015), bahwa return on sales tidak berpengaruh terhadap kinerja perusahaan. Shahwan (2015), menyatakan bahwa tidak ditemukan pengaruh yang signifikan antara corporate governance terhadap financial distress. Sedangkan penelitian yang dilakukan oleh Noviandri (2014), ditemukan bahwa return on sales berpengaruh positif terhadap financial distress.

Firm Size. Ukuran perusahaan terbagi dalam tiga kategori yaitu perusahaan besar perusahaan menengah dan perusahaan kecil. Secara teoritis perusahaan yang lebih besar mempunyai kepastian yang lebih besar dari pada perusahaan kecil, sehingga akan menggurangi tingkat ketidakpastian mengenai kesempatan perubahaan dimasa depan. Wright et al. (2009), menemukan bahwa ukuran perusahaan berpengaruh positif terhadap kinerja. Shahwan (2015) dan Talebria et al. (2010), menemukan bahwa tidak terdapat pengaruh ukuran perusahaan terhadap kinerja perusahaan. Putri dan Merkusiwati (2014), menunjukan bahwa ukuran perusahaan yang diukur menggunakan log of total asset memberikan pengaruh negatif terhadap financial distress. Shahwan (2015), menyatakan bahwa ukuran perusahaan yang diukur menggunakan log of total assets tidak memiliki pengaruh terhadap financial distress.

Capital Intensity. Capital intensity merupakan rasio antara net fixed assets terhadap total assets. dimana rasio ini menggambarkan besar aset perusahaan yang diinvestasikan dalam bentuk aset tetap yang dibutuhkan perusahaan untuk beroperasi. Martono (2002), menemukan pengaruh negatif dan signifikan antara capital intensity terhadap kinerja perusahaan. Shahwan (2015), tidak menemukan pengaruh antara capital intensity terhadap kinerja perusahaan. Pourali et al. (2013), menemukan adanya pengaruh negatif antara capital intensity terhadap financial distress.

Ownership Type. Menurut Hanousek et al. (2007), terdapat tiga kategori tipe kepemilikan menjadi yaitu kepemilikan domestik, asing dan pemerintah. Windah dan Andono (2013), berpendapat bahwa kepemilikan BUMN yang positif terhadap kemungkinan kesulitan keuangan karena mereka memiliki motif yang berbeda untuk memanipulasi pendapatan mereka, khususnya sebelum membuat initial public offerings. Penelitian yang dilakukan oleh Shahwan (2015), menemukan bahwa ownership type tidak memiliki pengaruh terhadap kinerja perusahaan, namun ownership type ditemukan memiliki pengaruh positif signifikan terhadap financial distress.

Ownership Concentration. Konsentrasi kepemilikan adalah sejumlah saham perusahaan yang tersebar dan dimiliki oleh beberapa pemegang saham. Jensen dan Meckling (1976) menyatakan bahwa manajer perusahaan yang mempunyai tingkat kepemilikan tinggi 
terhadap perusahaan, maka kemungkinan untuk melakukan ekspropriasi terhadap sumber daya perusahaan akan berkurang. Shahwan (2015), menyatakan bahwa ownership concentration tidak memiliki pengaruh yang signifikan terhadap kinerja perusahaan maupun terhadap financial distress. Ehikioya (2009), menemukan bahwa adanya kepemilikan yang terkonsentrasi baik di tangan individu maupun institusional lebih baik bagi para pemegang saham untuk melakukan proses monitoring sehingga dapat berdampak baik pada kinerja keuangan perusahaan. Li et al. (2008), menunjukkan adanya pengaruh negatif ownership concentration terhadap kemungkinan financial distress.

Institutional Ownership. Kepemilikan institusional merupakan salah satu faktor yang dapat mempengaruhi kinerja perusahaan. Dengan adanya kepemilikan oleh investor institusional dapat mendorong peningkatan pengawasan yang lebih optimal terhadap kinerja manajemen, Shahwan (2015), tidak menemukan pengaruh yang signifikan antara kepemilikan institusional terhadap kinerja perusahaaan. Charfeddine dan Elmarzougui (2011), menemukan bahwa institutional ownership tidak berpengaruh terhadap kinerja perusahaan. Laurenzia (2015), menyatakan institutional ownership berpengaruh positif terhadap financial distress.

\section{RERANGKA KONSEPTUAL}

Pada penelitian sebelumnya, Wang dan Deng (2006), menyatakan hubungan negatif financial distress dan corporate governance karena besar kepemilikan pemegang saham, kepemilikan negara, dan proporsi direksi independen. Ehikoya (2009), meneliti pengaruh antara yang hasilnya melaporkan adanya hubungan positif struktur corporate governance dan kinerja perusahaan dimana struktur kepemilikan yang sangat terkonsentrasi melindungi kepentingan investor dan pemangku kepentingan lainnya. Writh et al (2009), menunjukkan bahwa penerapan good corporate governance secara signifikan dapat meningkatkan return on equity, net profit margin, serta Tobin's $Q$. Mengenai hubungan antara corporate governance dan financial distress, Parker et al. (2002), menemukan bahwa leverage secara negatif berhubungan dengan kecenderungan bangkrut. Parker et al. (2002), menyatakan bahwa perusahaan dengan current ratio dan return on sales yang rendah lebih mungkin untuk bangkrut. Menurut Fama dan French (1992), book to market ratio yang tinggi mengilustrasikan sebuah persepsi pasar yang negatif dari prospek perusahaan dan tingkat resiko pasar yang lebih tinggi, secara konsisten meningkatkan kecenderungan bangkrut. Ismail (2016), menemukan bahwa semakin besar kepemilikan oleh institusi maka akan semakin besar kekuatan suara dan dorongan institusi untuk mengawasi manajemen dan akibatnya akan memberikan dorongan yang lebih besar untuk memaksimalkan nilai perusahaan sehingga kinerja perusahaan juga akan meningkat.

Rerangka konseptual. Putri dan Merkusiwati (2014), menunjukkan bahwa penerapan good corporate governance secara signifikan dapat meningkatkan kinerja perusahaan yang diukur dengan return on equity, net profit margin, serta Tobin's $Q$. Menurut Klapper dan Love (2002), menunjukan bahwa adanya hubungan positif yang signifikan dari corporate governance terhadap kinerja perusahaan yang diukur dengan ROA dan Tobin's Q. Sedangkan dalam penelitian yang dilakukan oleh Windah dan Andono (2013), menyatakan bahwa adanya pengaruh positif dan signifikan antara penerapan corporate governance terhadap kinerja perusahaan yang diukur dengan ROE. Berdasarkan penelitian di atas maka dapat dirumuskan hipotesis sebagai berikut: 
H1 : Pelaksanaan corporate governance berpengaruh terhadap kinerja perusahaan.

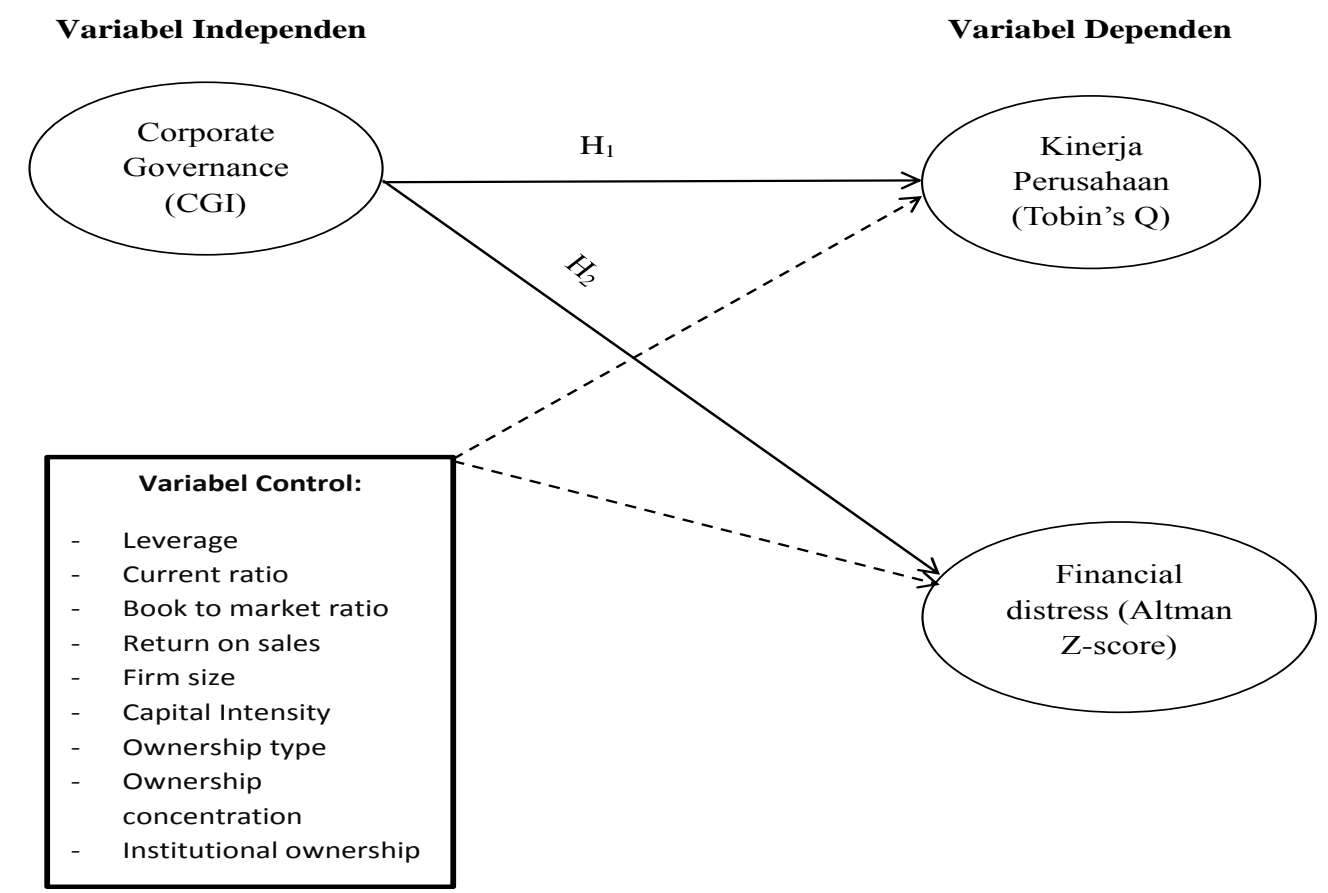

Gambar 1. Rerangka Konseptual

Wang dan Deng (2006), menyatakan hubungan negatif financial distress dan corporate governance karena besar kepemilikan pemegang saham, kepemilikan negara, dan proporsi direksi independen. Shahwan (2015), menemukan bawa terdapat perngaruh negatif signifikan antara praktek corporate governance yang diukur dengan CGI terhadap financial distress. Darmawan (2016), menemukan bahwa corporate governance yang diukur dengan corporate governance perception index berpengaruh negatif dan signifikan terhadap financial distress. Berdasarkan penelitian di atas maka dapat dirumuskan hipotesis sebagai berikut:

H2: Pelaksanaan corporate governance berpengaruh terhadap kemungkinan financial distress.

\section{METODE}

Metode pengumpulan data yang digunakan adalah pengumpulan data sekunder, dimana data sekunder merupakan data yang diperoleh peneliti secara tidak langsung atau data yang diperoleh dari penelitian orang lain atau sumber lain yang dipublikasikan. Metode penarikan sampel yang digunakan dalam penelitian ini adalah non- probability sampling dengan cara purposive sampling, artinya bahwa populasi yang dijadikan sampel penelitian adalah perusahaan yang memenuhi kriteria tertentu. Kriteria-kriterianya adalah sebagai berikut: (1) Perusahaan yang dijadikan sampel penelitian adalah perusahaan dari industri manufaktur yang terdaftar di Bursa Efek Indonesia untuk periode 2011 - 2015; (2) Perusahaan industri manufaktur yang menyediakan annual report lengkap sesuai data 
yang dibutuhkan selama periode 2011 - 2015; (3) Perusahaan yang mengeluarkan laporan keuangan dengan menggunakan mata uang rupiah.

Variabel Dan Pengukuran. Variabel-variabel yang digunakan dalam penelitian ini adalah corporate governance, kinerja perusahaan, financial distress, leverage, current ratio, book to market ratio, return on sales, firm size, capital intensity, institutional ownership, ownership concentration, dan ownership type. Pengukuran untuk variabelvariabel tersebut dapat dilihat pada Tabel 1 .

Tabel 1. Variabel dan Pengukuran

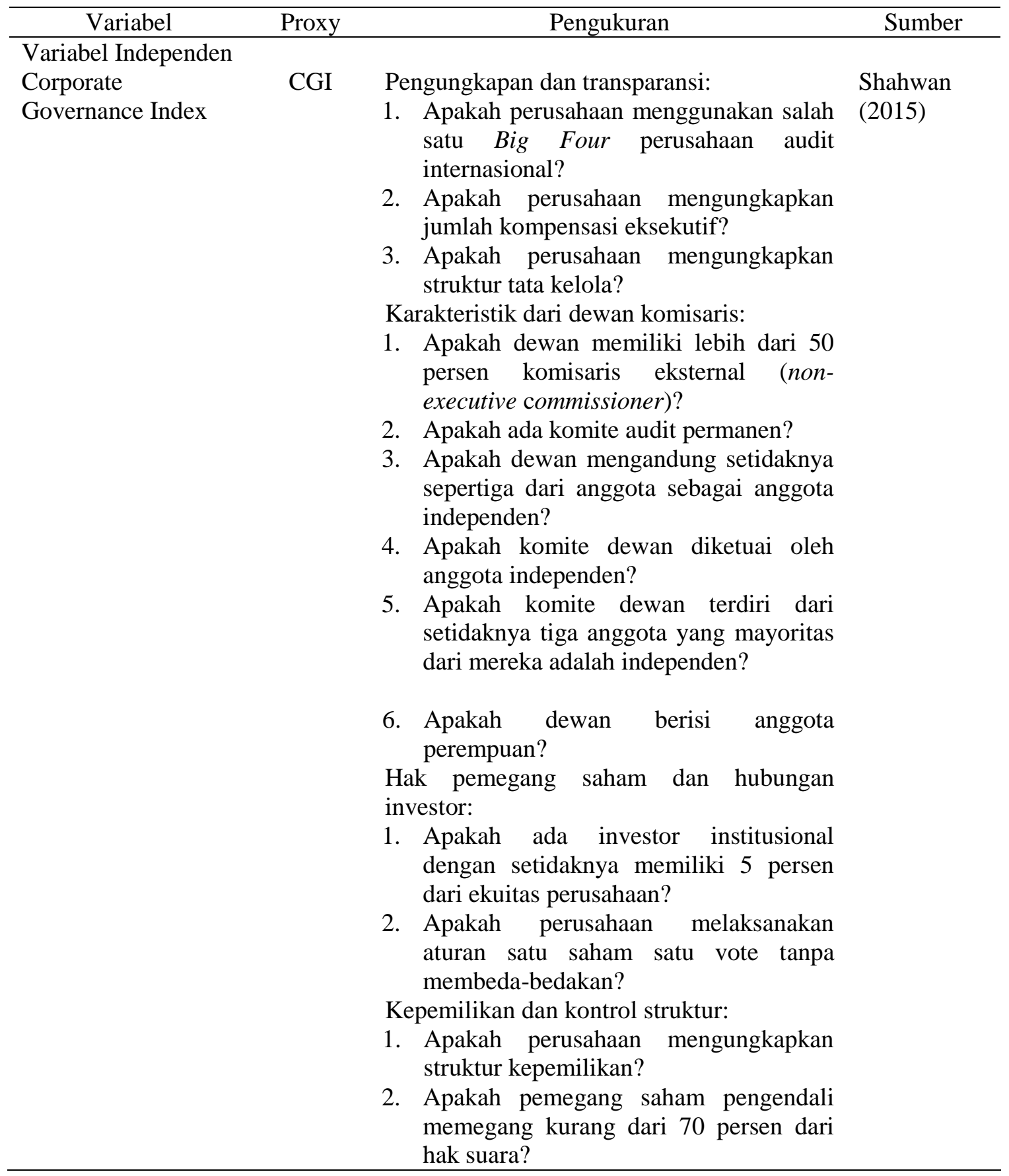


Variabel Dependen

Kinerja Perusahaan

Financial Distress
Tobin's
Q

Z-Score

3. Apakah perusahaan memiliki opsi saham karyawan (ESOP)?

4. Apakah ada konsentrasi kepemilikan dimana setidaknya 5 persen dari kepemilikan ekuitas perusahaan dipegang oleh investor?

\begin{tabular}{|c|c|c|}
\hline & \multirow[b]{2}{*}{$\mathrm{Q}$} & \\
\hline & & $\begin{array}{c}\text { Total } \text { Assets } \\
\mathrm{MVE}=\text { Closing Price } \times \text { Outstanding Share }\end{array}$ \\
\hline Financial Distress & Z-Score & $\begin{array}{l}Z \text { Score }=b_{1} X_{1}+b_{2} X_{2}+b_{3} X_{3}+b_{4} X_{4}+b_{5} X_{5} \\
X_{1} \text { Working Capital/Total Assets. } \\
X_{2} \text { Retained Earnings/Total Assets. } \\
X_{3} \text { EBIT/Total Assets. } \\
X_{4} \text { Market Value of Equity/Book Value of } \\
\text { Total Liabilities. } \\
X_{5} \text { Sales/Total Assets. }\end{array}$ \\
\hline
\end{tabular}

Variable Control

Leverage

LEV

Current Ratio

CR

Book to Market

BMR

Ratio

Return On Sales

ROS

SIZE

Firm Size
CAP_IN
$\mathrm{T}$

Ownership Type

Ownership

Concentration

$\frac{\text { Total Liabilities }}{\text { Total Assets }}$

Shahwan

Current Assets

Current Liabilities

Book Value of Equity

Market Value of Equity

$\frac{\text { EBIT }}{\text { Sales }}$

Logaritm Total Assets

Shahwan

(2015)

Shahwan

(2015)

Shahwan

(2015)

$$
\frac{\text { Net Fixed Assets }}{\text { Total Assets }}
$$

Pruitt

(1994);

Margaretha

Altman

(1968)

Shahwan

(2015)

Shahwan

(2015)

Shahwan

(2015)

jika perusahaan milik negara, jika tidak "0"

Shahwan

(2015)

Diukur dengan persentase saham yang dimiliki oleh pemegang saham terbesar

Institutional

INS_OW

Ownership

$\mathrm{N}$

Diukur dengan persentase saham yang dimiliki oleh investor institusional

Shahwan (2015)

\section{METODE}

Analisa dilakukan dengan menggunakan model regresi data panel untuk corporate governance dan kinerja perusahaan. Perumusannya adalah sebagai berikut: 


$$
\begin{gathered}
\text { PERF }=\beta_{0}+\beta_{1}(C G I)+\beta_{2}(L E V)+\beta_{3}(C R)+\beta_{4}(B M R)+\beta_{5}(R O S)+\beta_{6}(S I Z E) \\
+\beta_{7}\left(C A P_{-} I N T\right)+\beta_{8}\left(O W N_{-} C O N S\right)+\beta_{9}\left(I N S_{-} O W N\right)+\varepsilon
\end{gathered}
$$

Analisa dilakukan dengan menggunakan model regresi logistik untuk corporate governance dan financial distress. Perumusannya adalah sebagai berikut:

$$
\begin{gathered}
F D=\alpha_{0}+\alpha_{1}(C G I)+\alpha_{2}(L E V)+\alpha_{3}(C R)+\alpha_{4}(B M R)+\alpha_{5}(R O S)+\alpha_{6}(S I Z E) \\
+\alpha_{7}\left(C A P_{-} I N T\right)+\alpha_{8}(\text { OWN_CONS })+\alpha_{9}\left(I N S_{-} O W N\right)+\varepsilon
\end{gathered}
$$

$\begin{array}{ll}\text { Dimana: } & \\ \text { CGI } & \text { : Corporate Governance Index. } \\ \text { LEV } & : \text { Leverage. } \\ \text { CR } & : \text { Current Ratio. } \\ \text { BMR } & : \text { Book to Market Ratio. } \\ \text { ROS } & : \text { Return On Sales. } \\ \text { SIZE } & : \text { Log of Total Assets. } \\ \text { CAP_INT } & : \text { Capital Intensity. } \\ \text { OWN_CONS } & : \text { Ownership Concenration. } \\ \text { INS_OWN } & : \text { Institutional Ownership. }\end{array}$

Untuk menguji pengaruh corporate governance terhadap financial distress dilakukan analisis terhadap data terlebih dahulu. Pengujian terhadap data yang telah diperoleh dengan analisis diskriminan. Tujuan dari analisis diskriminan adalah untuk mengetahui variabel independen mana yang mendiskriminankan antara kelompok financial distress dan non financial distress. untuk kategori perusahaan financial distress diberi skor "0" dan untuk kategori non financial distress diberi skor "1". Test of Equality of Group Means yang dilakukan dengan tujuan untuk menguji perbedaan 2 rata-rata untuk masing-masing kelompok. Hipotesis yang digunakan adalah:

a. $\mathrm{H}_{\mathrm{o}}: \mu_{1}=\mu_{2}$ artinya tidak ada perbedaan rata-rata untuk kelompok perusahaan financial distress dan non financial distress

b. $\mathrm{H}_{\mathrm{a}}: \mu_{1} \neq \mu_{2}$ artinya ada perbedaan rata-rata untuk kelompok perusahaan financial distress dan non financial distress

Uji $\mathrm{T}$ dilakukan untuk menguji bagaimana pengaruh masing-masing variabel independen terhadap variabel dependen. Adapun kriteria keputusannya adalah sebagai berikut:

a. Jika $\mathrm{p}$ value $>0.05$ artinya variabel independen tidak mempengaruhi variabel dependen.

b. Jika p value $<0.05$ artinya variabel independen mempengaruhi variabel dependen.

\section{HASIL DAN PEMBAHASAN}

Objek penelitian dalam penelitian ini adalah perusahaan yang bergerak dalam industri manufaktur yang terdaftar di Bursa Efek Indonesia (BEI) selama periode 2011 2015. Dengan jumlah sampel awal sejumlah 141 perusahaan, kemudian setelah melakukan purposive sampling, sampel yang memenuhi kriteria dalam penelitian ini sejumlah 72 perusahaan. Berikut akan disajikan statistik deskriptif dari variabel independen maupun 
variabel dependen. Analisis statistik deskriptif menunjukan nilai minimum, nilai maksimum, nilai rata-rata serta standar deviasi dari masing-masing variabel.

Tabel 2. Statistik Deskriptif

\begin{tabular}{lrrrrr}
\hline \multicolumn{1}{c}{ Variabel } & N & Minimum & Maximum & Mean & $\begin{array}{c}\text { Std. } \\
\text { Deviation }\end{array}$ \\
\hline CGI & 360 & .2667 & .7333 & .5239 & .0840 \\
LEV & 360 & .0372 & 3.0291 & .4936 & .3544 \\
CR & 360 & .3453 & 464.9844 & 4.3864 & 27.6440 \\
BMR & 360 & -7.5926 & 8.3550 & .9827 & 1.2363 \\
ROS & 360 & -1.9110 & .8086 & .0789 & .1501 \\
SIZE & 360 & 10.9416 & 14.3899 & 12.2295 & .7143 \\
CAP_INT & 360 & .0104 & .9481 & .3541 & .1996 \\
OWN_CONS & 360 & .1017 & .9782 & .5174 & .2360 \\
INS_OWN & 360 & .0081 & .9974 & .6981 & .1961 \\
TobinsQ & 360 & .3326 & 18.6404 & 1.8351 & 2.1145 \\
\hline
\end{tabular}

Sumber: data diolah dengan Eviews

Berdasarkan hasil pengolahan data pada tabel 2 diketahui bahwa variabel corporate governance mempunyai nilai rata-rata sebesar 0,5239 dan nilai standar deviasi sebesar 0,0840. Sedangkan nilai minimum 0,2667 sebesar dimiliki perusahaan Intanwijaya Internasional Tbk. dan JAPFA Comfeed Indonesia Tbk. dan nilai maksimum sebesar 0,7333 dimiliki perusahaan Jembo Cable Company Tbk., Bentoel Internasional Investama Tbk., Sierad Produce Tbk., Mandom Indonesia Tbk. dan Ultrajaya Milk Industry \& Trading Co. Tbk. Untuk variabel leverage mempunyai nilai rata-rata sebesar 0,4936 dan nilai standar deviasi sebesar 0,3544. Sedangkan nilai minimum sebesar 0,0372 dimiliki perusahaan Jaya Pari Steel Tbk. dan nilai maksimum sebesar 3,0291 dimiliki perusahaan Primarindo Asia Infrastructure Tbk. Untuk variabel current ratio mempunyai nilai rata-rata sebesar 4,3864 dan nilai standar deviasi sebesar 27,6440. Sedangkan nilai minimum sebesar 0,3453 dimiliki perusahaan Apac Citra Centertex Tbk. dan nilai maksimum 464,9844 sebesar dimiliki perusahaan Jaya Pari Steel Tbk. Untuk variabel book to market ratio mempunyai nilai rata-rata sebesar 0,9827 dan nilai standar deviasi sebesar 1,2363. Sedangkan nilai minimum sebesar -7,5926 dimiliki perusahaan Apac Citra Centertex Tbk. dan nilai maksimum sebesar 8,3550 dimiliki perusahaan Indospring Tbk. Untuk variabel return on sales mempunyai nilai rata-rata sebesar 0,0789 dan nilai standar deviasi sebesar 0,1501. Sedangkan nilai minimum sebesar $-1,9110$ dimiliki perusahaan Kertas Basuki Rachmat Indonesia Tbk. dan nilai maksimum sebesar 0,8086 dimiliki perusahaan Kertas Basuki Rachmat Indonesia Tbk. Untuk variabel firm size mempunyai nilai rata-rata sebesar 12,2295 dan nilai standar deviasi sebesar 0,7143. Sedangkan nilai minimum sebesar 10,9416 dimiliki perusahaan Kedaung Indah Can Tbk. dan nilai maksimum sebesar 14,3899 dimiliki perusahaan Astra International Tbk. Untuk variabel capital intensity mempunyai nilai rata-rata sebesar 0,3541 dan nilai standar deviasi sebesar 0,1996. Sedangkan nilai minimum sebesar 0,0104 dimiliki perusahaan Alakasa Industrindo Tbk. dan nilai maksimum sebesar 0,9481 dimiliki perusahaan Kertas Basuki Rachmat Indonesia Tbk. Untuk variabel ownership concentration mempunyai nilai ratarata sebesar 0,5174 dan nilai standar deviasi sebesar 0,2360. Sedangkan nilai minimum sebesar 0,1017 dimiliki perusahaan Kalbe Farma Tbk. dan nilai maksimum sebesar 0,9782 
dimiliki perusahaan Intanwijaya Internasional Tbk. Untuk variabel instritutional ownership mempunyai nilai rata-rata sebesar 0,6981 dan nilai standar deviasi sebesar 0,1961. Sedangkan nilai minimum sebesar 0,0081 dimiliki perusahaan pada Intanwijaya Internasional Tbk. dan nilai maksimum sebesar 0,9974 dimiliki perusahaan Semen Indonesia (Persero) Tbk. Untuk variabel kinerja perusahaan yang diukur dengan Tobin's Q mempunyai nilai rata-rata sebesar 1,8351 dan nilai standar deviasi sebesar 2,1145. Sedangkan nilai minimum sebesar 0,3326 dimiliki perusahaan Jaya Pari Steel Tbk. dan nilai maksimum sebesar 18,6404 dimiliki perusahaan Unilever Indonesia Tbk.

\begin{tabular}{ccc}
\multicolumn{4}{c}{ Tabel 3. Uji t Regresi Panel } \\
& Dependen Variabel: Tobin's Q \\
\hline Variabel & Koefisien & Prob \\
\hline C & 1.322285 & 0.1374 \\
CGI & 1.331891 & 0.2148 \\
LEV & -0.221910 & 0.6358 \\
CR & -0.000591 & 0.7110 \\
BMR & -0.198464 & 0.0002 \\
ROS & 0.249179 & 0.4355 \\
SIZE & -0.003472 & 0.6347 \\
CAP_INT & -2.969664 & 0.0001 \\
OWN_CONS & 5.353464 & 0.0000 \\
INS_OWN & -2.272838 & 0.0453 \\
\hline
\end{tabular}

Sumber: data diolah dengan Eviews

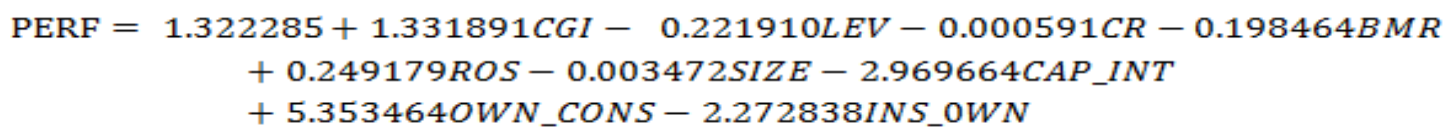

Corporate Governnace. Berdasarkan hasil analisis pada tabel 3, dengan probabilitas sebesar 0,2148 > 0,05 maka menunjukan bahwa tidak ada pengaruh antara pelaksanaan corporate governance terhadap kinerja perusahaaan. Corporate governance tidak berpengaruh terhadap kinerja perusahaan. Hasil ini tidak sesuai dengan penelitian Klapper dan Love (2002), hasil dari penelitiannya menunjukan bahwa adanya hubungan positif yang signifikan dari corporate governance terhadap kinerja perusahaan. Tetapi sesuai dengan penelitian yang dilakukan oleh Shahwan (2015), yang menyatakan bahwa pelaksanaan corporate governance tidak memiliki pengaruh terhadap kinerja perusahaan. Hal ini berarti baik atau tidak tata kelola yang dilaksanakan perusahaan tidak akan mempengaruhi kinerja suatu perusahaan.

\section{Variabel Kontrol}

1. Leverage. Berdasarkan hasil analisis pada Tabel 3, dengan probabilitas sebesar 0,6358 $>$ 0,05 maka menunjukkan bahwa tidak terdapat pengaruh antara leverage terhadap kinerja perusahaan. Hasil ini tidak sesuai dengan penelitian Shahwan (2015), yang menemukan adanya pengaruh positif antara leverage terhadap kinerja perusahaan. Tetapi sejalan dengan penelitian yang dilakukan oleh Syari (2014), yang menyatakan bahwa leverage tidak berpengaruh terhadap kinerja perusahaan. Hal ini menunjukan 
bahwa tinggi atau rendahnya nilai leverage tidak akan berpengaruh terhadap kinerja perusahaan.

2. Current Ratio. Berdasarkan hasil analisis pada Tabel 3, dengan probabilitas sebesar $0,7110>0,05$ maka menunjukkan bahwa tidak terdapat pengaruh antara current ratio terhadap kinerja perusahaan. Hasil ini tidak sesuai dengan penelitian yang dilakukan oleh Ismail (2016), menyatakan bahwa current ratio berpengaruh positif terhadap kinerja perusahaan. Tetapi sesuai dengan penelitian Yuniarta et al. (2015), menyatakan current ratio tidak berpengaruh terhadap kinerja perusahaan. Hal ini menunjukan bahwa current ratio yang tinggi juga tidak selalu menguntungkan perusahaan karena banyaknya dana menganggur yang pada akhirnya dapat mengurangi kemampuan perusahaan dalam memperoleh laba.

3. Book to Market Ratio. Berdasarkan hasil analisis pada Tabel 3, dengan probabilitas sebesar 0,0002 < 0,05 dan koefisien sebesar -0.198464 maka menunjukkan bahwa terdapat pengaruh negatif antara book to market ratio terhadap kinerja perusahaan. Hasil sesuai dengan penelitian Shahwan (2015), yang menemukan adanya pengaruh negatif book to market ratio terhadap kinerja perusahaan. Hal ini mengindikasi bahwa nilai book to market ratio yang tinggi menunjukkan bahwa perusahaan memiliki kinerja buruk, karena semakin rendah rasio ini menandakan semakin tinggi perusahaan dinilai oleh para investor.

4. Return On Sales. Berdasarkan hasil analisis pada Tabel 3, dengan probabilitas sebesar 0,4355>0,05 maka menunjukkan bahwa tidak terdapat pengaruh antara return on sales terhadap kinerja perusahaan. Hasil ini sesuai dengan penelitian yang dilakukan oleh Yuniarta et al. (2015), bahwa return on sales tidak berpengaruh terhadap kinerja perusahaan. Hal ini menunjukan bahwa tinggi atau rendahnya nilai return on sales tidak akan mempengaruhi kinerja suatu perusahaan.

5. Firm Size. Berdasarkan hasil analisis pada Tabel 3, dengan probabilitas sebesar 0,6347 $>$ 0,05 maka menunjukkan bahwa tidak terdapat pengaruh antara firm size terhadap kinerja perusahaan. Hasil ini tidak sesuai dengan penelitian yang dilakukan oleh Wright et al. (2009), menemukan bahwa ukuran perusahaan berpengaruh positif terhadap kinerja. Namun sejalan dengan penelitian Shahwan (2015), yang menemukan bahwa tidak terdapat pengaruh ukuran perusahaan terhadap kinerja perusahaan. Hal ini menunjukkan besar atau kecilnya suatu perusahaan tidak akan mempengaruhi kinerja perusahaannya.

6. Capital Intensity. Berdasarkan hasil analisis pada tabel 3, dengan probabilitas sebesar $0,0001<0,05$ dan koefisien sebesar -2.969664 maka menunjukkan bahwa terdapat pengaruh negatif antara capital intensity terhadap kinerja perusahaan. Hasil ini sesuai dengan penelitian Martono (2002), yang menemukan adanya pengaruh negatif antara capital intensity dengan kinerja perusahaan. Hal ini menunjukan bahwa semakin tinggi intensitas modal suatu perusahaan maka akan menghasilkan kinerja yang tidak efisien karena tingginya aset yang dibutuhkan agar perusahaan dapat terus beroperasi.

7. Ownership Concentration. Berdasarkan hasil analisis pada Tabel 3, dengan probabilitas sebesar $0,0000<0,05$ dan koefisien sebesar 5.353464 maka menunjukkan bahwa terdapat pengaruh positif antara ownership concentration terhadap kinerja perusahaan. Hasil ini sesuai dengan penelitian Ehikioya (2009), yang menemukan adanya pengaruh positif antara ownership concentration terhadap kinerja perusahaan. Hal ini menunjukan bahwa adanya kepemilikan terkonsentrasi lebih baik bagi para 
pemegang saham untuk melakukan proses monitoring sehingga dapat berdampak baik pada kinerja keuangan perusahaan.

8. Institutional Ownership. Berdasarkan hasil analisis pada Tabel 3, dengan probabilitas sebesar $0,0453<0,05$ dan koefisien sebesar -2.272838 maka menunjukkan bahwa terdapat pengaruh negatif antara institutional ownership terhadap kinerja perusahaan. Hasil sesuai dengan penelitian Charfeddine dan Elmarzougui (2011). yang menemukan pengaruh negatif antara institutional ownership terhadap kinerja perusahaan. Hal ini menunjukan bahwa investor institusional mayoritas berperan dalam pengendalian perusahaan sehingga cenderung bertindak untuk kepentingan mereka sendiri atau berpihak kepada manajemen dan mengabaikan kepentingan pemegang saham minoritas sehingga disaat kepemilikan institusional meningkat maka kinerja perusahaan akan menurun.

Tabel 4. Uji Beda Rata-Rata 2 Kelompok

\begin{tabular}{|c|c|c|c|c|}
\hline Variabel & Kelompok & Mean & Sig. & Kesimpulan \\
\hline Working Capital/Total Asset & $\begin{array}{l}\text { Distress } \\
\text { Non Distress }\end{array}$ & $\begin{array}{l}.0351 \\
.2590\end{array}$ & 0,000 & Ho ditolak \\
\hline Earnings/Total & $\begin{array}{l}\text { Distress } \\
\text { Non Distress }\end{array}$ & $\begin{array}{l}-.3034 \\
.2307\end{array}$ & 0,000 & Ho ditolak \\
\hline EBIT /Total Assets & $\begin{array}{l}\text { Distress } \\
\text { Non Distress }\end{array}$ & $\begin{array}{l}-.0143 \\
.1199\end{array}$ & 0,000 & Ho ditolak \\
\hline $\begin{array}{l}\text { Market Value of Equity/ } \\
\text { Book Value of Total Debt }\end{array}$ & $\begin{array}{l}\text { Distress } \\
\text { Non Distress }\end{array}$ & $\begin{array}{l}1.3131 \\
4.7014\end{array}$ & 0,000 & Ho ditolak \\
\hline Sales/Total Assets & $\begin{array}{l}\text { Distress } \\
\text { Non Distress }\end{array}$ & $\begin{array}{l}1.0462 \\
1.2145\end{array}$ & 0,069 & $\begin{array}{l}\text { Ho gagal } \\
\text { ditolak }\end{array}$ \\
\hline
\end{tabular}

Sumber: data diolah dengan SPSS

Hasil dari uji beda rata-rata 2 kelompok (Tabel 4) pada kelompok perusahaan financial distress memiliki nilai rata-rata rasio working capital/total assets sebesar 0,0351 sedangkan untuk perusahaan non financial distress sebesar 0,2590 dan nilai signifikansi untuk perbedaan kedua kelompok tersebut adalah $0,000<0,05$ sehingga $\mathrm{H}_{\mathrm{o}}$ ditolak atau ada perbedaan rata-rata rasio working capital/total assets antara kelompok financial distress dan non financial distress. Perusahaan yang mengalami financial distress memiliki nilai rasio modal kerja yang lebih rendah dibandingkan dengan perusahaan yang non financial distress.

Pada kelompok perusahaan financial distress memiliki nilai rata-rata rasio retained earningst/total assets sebesar -0,3043 sedangkan untuk perusahaan non financial distress sebesar 0,2307 dan nilai signifikansi untuk perbedaan kedua kelompok tersebut adalah $0,000<0,05$ sehingga $\mathrm{H}_{\mathrm{o}}$ ditolak atau ada perbedaan rata-rata rasio retained earnings/total assets antara perusahaan yang financial distress dan non financial distress. Perusahaan yang mengalami financial distress memiliki nilai rasio laba ditahan yang lebih rendah dibandingkan dengan perusahaan yang non financial distress.

Pada kelompok perusahaan financial distress memiliki nilai rata-rata rasio EBIT/total assets sebesar -0,0143 sedangkan untuk perusahaan non financial distress sebesar 0,1199 dan nilai signifikansi untuk perbedaan kedua kelompok tersebut adalah $0,000<0,05$ sehingga $\mathrm{H}_{\mathrm{o}}$ ditolak atau ada perbedaan rata-rata rasio EBIT/total assets antara perusahaan yang financial distress dan non financial distress. Perusahaan yang 
mengalami financial distress memiliki nilai rasio EBIT/total assets yang lebih rendah dibandingkan dengan perusahaan yang non financial distress.

Pada kelompok perusahaan financial distress memiliki nilai rata-rata rasio market value of equity/book value of total debt sebesar 1,3131 sedangkan untuk perusahaan non financial distress sebesar 4,7014 dan nilai signifikansi untuk perbedaan kedua kelompok tersebut adalah $0,000<0,05$ sehingga $\mathrm{H}_{\mathrm{o}}$ ditolak atau ada perbedaan rata-rata rasio market value of equity/book value of total debt antara perusahaan yang financial distress dan non financial distress. Perusahaan yang mengalami financial distress memiliki nilai rasio market value of equity/book value of total debt yang lebih rendah dibandingkan dengan perusahaan yang non financial distress.

Pada kelompok perusahaan financial distress memiliki nilai rata-rata rasio sales/total assets sebesar 1,0462 sedangkan untuk perusahaan non financial distress sebesar 1,2145 dan nilai signifikansi untuk perbedaan kedua kelompok tersebut adalah 0,069>0,05 sehingga $\mathrm{H}_{\mathrm{o}}$ gagal ditolak atau tidak ada perbedaan rata-rata rasio sales/total assets antara perusahaan yang financial distress dan non financial distress.

Tabel 5. Stepwise Statistics

\begin{tabular}{lrrr}
\hline Step & & Sig. of F to Enter & \multicolumn{2}{c}{ Wilks' Lambda } \\
\hline 0 & X1 & .000 & .879 \\
& X2 & .000 & .879 \\
& X3 & .000 & .739 \\
& X4 & .000 & .951 \\
& X5 & .069 & .991 \\
1 & X1 & .000 & .667 \\
& X2 & .000 & .696 \\
& X4 & .004 & .722 \\
& X5 & .395 & .737 \\
2 & X2 & .041 & .659 \\
& X4 & .000 & .628 \\
3 & X5 & .785 & .667 \\
& X2 & .020 & .618 \\
4 & X5 & .218 & .625 \\
& X5 & .250 & .616 \\
\hline
\end{tabular}

Sumber: data diolah dengan SPSS

Hasil dari stepwise statistics (Tabel 5) sehingga dapat terlihat pada setiap tahapan variabel mana yang paling mendiskriminan atau membedakan kelompok perusahaan financial distress dan non financial distress. Pada tahap 0 ketika semua variabel independen dimasukkan, yang keluar sebagai variabel pertama yang mendiskriminankan adalah $\mathrm{X}_{3}$ (EBIT/total assets) dengan nilai wilks lamba 0,739 dan nilai sig 0,000<0,05. Pada tahap 1 variabel kedua yang mendiskriminankan adalah $\mathrm{X}_{1}$ (working capital/total assets) dengan nilai wilks lamba 0,667 dan nilai sig $0,000<0,05$. Pada tahap 2 variabel ketiga yang mendiskriminankan adalah $\mathrm{X}_{4}$ (market value of equity/book value of total debt) dengan nilai wilks lamba 0,628 dan nilai sig $0,000<0,05$. Pada tahap 3 variabel ketiga yang mendiskriminankan adalah $\mathrm{X}_{2}$ (retained earnings/total assets) dengan nilai wilks lamba 0,618 dan nilai sig 0,020 $<0,05$. Sedangkan pada tahap 4 , variabel $\mathrm{X}_{5}$ (sales/total assets) tidak menjadi variabel yang mendiskriminankan karena nilai sig 0,250 $>0,05$.

Berdasarkan hasil dari fungsi diskriminan (Tabel 6). Maka terdapat bentuk persamaan: 
$\mathrm{Z}=-1,426+12,829($ EBIT/Total Assets) $+2,292$ (Working Capital/Total Assets) 0,098 (Market Value of Equty/Book Value of Total Liabilities) + 0,425 (Retained Earnings/Total Assets).

Maka suatu perusahaan masuk dalam kelompok financial distress jika nilai $\mathrm{Z}$ skor yang dimiliki adalah $<-1.787$. Sedangkan suatu perusahaan masuk ke dalam kelompok non financial distress jika nilai Z skor yang dimiliki adalah $>0.343$.

Tabel 6. Fungsi Diskriminan

\begin{tabular}{lccc}
\hline \multicolumn{1}{c}{ Variabel } & \multirow{2}{*}{ Koefisien } & \multicolumn{2}{c}{ Function of Group Centroid } \\
\cline { 3 - 4 } & $-1,426$ & Distress & Non Distress \\
\hline Konstanta & 12,829 & & \\
EBIT/Total Assets & 2,292 & & \\
Working Capital/ & & $-1,787$ & 0,343 \\
$\begin{array}{l}\text { Total Asset } \\
\text { Market Value of Equity/ }\end{array}$ & $-0,098$ & & \\
$\begin{array}{l}\text { Book Value of Total Debt } \\
\text { Retained Earnings/ }\end{array}$ & 0,425 & & \\
Total Asset & & & \\
\hline
\end{tabular}

Sumber: data diolah dengan SPSS

Tabel 7. UJI T Regresi Logistik

Variabel Dependen: Financial Distress

\begin{tabular}{lcc}
\hline \multicolumn{1}{c}{ Variabel } & Koefisien & Prob \\
\hline C & 5.665 & .006 \\
CGI & -5.220 & .046 \\
LEV & -1.415 & .018 \\
CR & -.008 & .527 \\
BMR & .413 & .060 \\
ROS & 70.856 & .000 \\
SIZE & -.021 & .091 \\
CAP_INT & -8.451 & .000 \\
OWN_CONS & -2.267 & .069 \\
INS_OWN & -.855 & .586 \\
\hline
\end{tabular}

Sumber: data diolah dengan SPSS

$\mathrm{FD}=5.665-5.220 C G I-1.415 L E V-0.008 C R+0.413 B M R+70.856 R O S-0.021$ SIZE 8.451CAP_INT - 2.267OWN_CONS - 0.855INS_OWN

Corporate Governance. Berdasarkan hasil analisis pada Tabel 7, dengan probabilitas sebesar 0,046 $<0,05$ dan koefisien sebesar $-5,220$ maka menunjukan terdapat pengaruh negatif antara pelaksanaan corporate governance terhadap kemungkinan financial distress. Hasil ini sesuai dengan penelitian Wang dan Deng (2006), yang menemukan adanya pengaruh negatif antara pelaksanaan corporate governance terhadap kemungkinan financial distress. Hal ini menunjukan bahwa semakin baik tata kelola yang dilaksanakan oleh perusahaan maka kemungkinan terjadinya financial distress akan menurun. 


\section{Variabel Kontrol}

1. Leverage. Berdasarkan hasil analisis pada Tabel 7, dengan probabilitas sebesar 0,018 $<0,05$ dan koefisien sebesar -1,415 maka menunjukkan bahwa terdapat pengaruh negatif antara leverage terhadap kemungkinan financial distress. Hasil sesuai dengan penelitian Parker et al. (2002), bahwa ada pengaruh negatif antara leverage terhadap kemungkinan financial distress. Hal ini menunjukan bahwa perusahaan yang memiliki leverage tinggi berarti perusahaan mempunyai kemampuan yang rendah dalam melakukan pembayaran utangnya sehingga kemungkinan perusahaan mengalami financial distress akan meningkat.

2. Current Ratio. Berdasarkan hasil analisis pada Tabel 7 , dengan probabilitas sebesar 0,527>0,05 maka menunjukkan bahwa tidak terdapat pengaruh antara current ratio terhadap kemungkinan financial distress. Hasil ini tidak sesuai dengan penelitian Shahwan (2015), yang menemukan current ratio memiliki pengaruh negatif signifikan terhadap financial distress. Tetapi sesuai dengan penelitian Putri dan Merkusiwati (2014), menyatakan current ratio tidak berpengaruh terhadap financial distress. Hal ini mengindikasikan karena tiap perusahaan memerlukan waktu yang tidak berbedabeda untuk mengkonversi piutang usaha dan persediaan dalam bentuk kas yang akan digunakan untuk membiayai kewajiban perusahaan. Maka tinggi atau rendahnya current ratio perusahaan tidak akan mempengaruhi kemungkinan perusahaan mengalami financial distress.

3. Book to Market Ratio. Berdasarkan hasil analisis pada Tabel 7, dengan probabilitas sebesar 0,060 < 0,05 maka menunjukkan bahwa tidak terdapat pengaruh antara book to market ratio terhadap kemungkinan financial distress. Hasil ini tidak sesuai dengan penelitian Vassalou dan Xing (2004), bahwa menemukan adanya prngaruh positif book to market ratio dengan kemungkinan kebangkrutan. Tetapi sesuai dengan penelitian Shahwan (2015), bahwa book to market ratio tidak berpengaruh terhadap kemungkinan financial distress. Hal ini menunjukan bahwa tinggi atau rendah nilai book to market ratio tidak akan berpengaruh terhadap kemungkinan terjadinya financial distress.

4. Return On Sales. Berdasarkan hasil analisis pada Tabel 7, dengan probabilitas sebesar $0,000<0,05$ dan koefisien sebesar 70,856 maka menunjukkan bahwa terdapat pengaruh positif antara return on sales terhadap kemungkinan financial distress. Hasil sesuai dengan penelitian Noviandri (2014), bahwa terdapat pengaruh positif antara return on sales terhadap kemungkinan financial distress. Hal ini menunjukan bahwa semakin besar nilai return on sales maka kemungkinan perusahaan mengalami financial distress semakin meningkat. Karena semakin lama proses penjualan akan menambah beban perusahaan dan resiko kerugian juga akan meningkat.

5. Firm Size. Berdasarkan hasil analisis pada Tabel 7 , dengan probabilitas sebesar 0,091 $<0,05$ maka menunjukkan bahwa tidak terdapat pengaruh antara firm size terhadap kemungkinan financial distress. Hasil ini tidak sesuai dengan penelitian yang dilakukan oleh Putri dan Merkusiwati (2014), menunjukan bahwa ukuran perusahaan berpengaruh negatif terhadap financial distress. Tetapi sesuai dengan penelitian Shahwan (2015) yang pada penelitiannya juga tidak menemukan adanya pengaruh antara firm size terhadap financial distress. Hal ini menunjukkan besar atau kecilnya perusahaan tidak dapat menentukan perusahaan akan mengalami kondisi financial distress 
6. Capital Intensity. Berdasarkan hasil analisis pada Tabel 7, dengan probabilitas $0,000<$ 0,05 dan koefisien sebesar -8,451 maka menunjukkan bahwa terdapat pengaruh negatif antara capital intensity terhadap kemungkinan financial distress. Hasil ini sesuai dengan penelitian Pourali et al. (2013), yang menemukan adanya pengaruh negatif capital intensity terhadap financial distress. Hal ini menunjukan bahwa apabila aset tetap digunakan dengan optimal maka perusahaan akan memperoleh keuntungan yang optimal juga maka kemungkinan mengalami financial distress akan berkurang.

7. Ownership Concentration. Berdasarkan hasil analisis pada Tabel 7, dengan probabilitas sebesar 0,069 0,05 maka menunjukkan bahwa tidak terdapat pengaruh antara ownership concentration terhadap kemungkinan financial distress. Hasil ini tidak sesuai dengan penelitian yang dilakukan oleh Li et al., (2008), menunjukkan adanya pengaruh negatif ownership concentration terhadap kemungkinan financial distress. Tetapi sesuai dengan penelitian Shahwan (2015), bahwa tidak terdapat pengaruh antara ownership concentration terhadap kemungkinan financial distress. Hal ini menunjukan bahwa besarnya ownership concentration tidak dapat mempengaruhi perusahaan terhindar dari kemungkinan financial distress.

8. Institutional Ownership. Berdasarkan hasil analisis pada Tabel 7, dengan probabilitas sebesar 0,586 $<0,05$ maka menunjukkan bahwa tidak terdapat pengaruh antara institutional ownership terhadap kemungkinan financial distress. Hasil ini tidak sesuai dengan penelitian yang dilakukan oleh Laurenzia (2015), menyatakan institutional ownership berpengaruh positif terhadap financial distress. Tetapi sesuai dengan penelitian Shahwan (2015), menyatakan bahwa tidak terdapat pengaruh antara institutional ownership terhadap financial distress. Kepemilikan saham oleh institusi yang besar merupakan pemilik mayoritas dan terpusat, yang menyebabkan berkurangnya transparasi penggunaan dana perusahaan. Hal tersebut menyebabkan tinggi rendahnya kepemilikan institusional tidak berpengaruh terhadap kondisi financial distress.

\section{PENUTUP}

Simpulan. Penelitian ini bertujuan untuk mengetahui bagaimana pengaruh antara corporate governance terhadap kinerja perusahaan dan financial distress. Berdasarkan analisis dan pembahasan yang telah dilakukan, maka dapat diambil kesimpulan sebagai berikut: (1) Corporate governance tidak berpengaruh terhadap kinerja perusahaan; (2) Corporate governance berpengaruh negatif terhadap kemungkinan financial distress.

Penelitian ini juga menggunakan variabel leverage, current ratio, book to market ratio, return on sales, firm size, capital intensity, institutional ownership, dan ownership concentration sebagai variabel kontrol untuk mengetahui bagaimana pengaruhnya terhadap kinerja perusahaan dan financial distress. berdasarkan analisis yang telah dilakukan, maka kesimpulannya adalah sebagai berikut: (a) Leverage tidak berpengaruh terhadap kinerja perusahaan; (b) Current ratio tidak berpengaruh terhadap kinerja perusahaan; (c) Book to market ratio memiliki pengaruh negatif terhadap kinerja perusahaan; (d) Return on sales tidak berpengaruh terhadap kinerja perusahaan; (e) Firm size tidak berpengaruh terhadap kinerja perusahaan; (f) Capital intensity berpengaruh negatif terhadap kinerja perusahaaan; (g) Ownership concentration berpengaruh positif terhadap kinerja perusahaan; (h) Institutional ownership berpengaruh negatif terhadap kinerja perusahaan; (i) Leverage berpengaruh negatif terhadap kemungkinan financial 
distress; (j) Current Ratio tidak berpengaruh terhadap kemungkinan financial distress; (k) Book to market ratio tidak berpengaruh terhadap kemungkinan financial distress; (1) Rerturn on sales berpengaruh positif terhadap kemungkinan financial distress; (m) Firm size tidak berpengaruh terhadap kemungkinan financial distress; (n) Capital intensity berpengaruh negatif terhadap kemungkinan financial distress; (n) Ownership concentration tidak berpengaruh terhadap kemungkinan financial distress; (o) Institutional ownership tidak berpengaruh pengaruh terhadap kemungkinan financial distress.

Implikasi Manajerial. Pertama. Bagi perusahaan. Agar perusahaaan terhindar dari kemungkinan terjadinya financial distress sebaiknya perusahaan meningkatkan pelaksanaan corporate governance karena semakin baik pelaksanaan corporate governance maka kemungkinan terjadinya financial distress akan menurun. Lalu sebaiknya perusahaan mengoptimalkan penggunaan fixed assets sehingga perusahaan dapat meningkatkan penjualannya karena apabila penjualannya meningkat maka perusahaan akan mendapatkan return on sales yang optimal serta harus diikuti oleh kegiatan yang efektif dan efisien sehingga dapat membayar utang-utang perusahaan.

Kedua. Bagi investor. Sebelum melakukan investasi, investor sebaiknya mempertimbangkan faktor-faktor yang dapat memprediksi kondisi perusahaan apakah perusahaan tersebut sehat atau berkemungkinan mengalami financial distress, yaitu bagaimana pelaksanaan corporate governance, penggunanan fixed asset, tingkat leverage, serta return on sales suatu perusahaan. Hal ini perlu diperhatikan agar investor mengetahui bagaimana kondisi perusahaan tersebut untuk memperoleh keuntungan dari investasi yang dilakukan.

\section{DAFTAR RUJUKAN}

Abdullah, S.N. (2006) "Board Structure and Ownership in Malaysia: The Case of Distressed Listed Companies", Corporate Governance: The International Journal of Business in Society, 6 (5), 582-594.

Al-Matari E.M, Al-Swidi A. K, Bt Fadzil F.H. (2014) "The Measurements of Firm Performance's Dimensions", Asian Journal of Finance \& Accounting, 6 (1), 24-49.

Altman, E.I. (1968) "Financial Ratios, Discriminant Analysis and The Prediction of Corporate Bankruptcy", The Journal of Finance, 23 (4), 589-609.

Beaver, W. H., Correia, M. and McNichols, M. F. (2010) "Financial Statement Analysis and the Prediction of Financial Distress". Foundations and Trends in Accounting, 5 (2), 99-173.

Cadbury Committee, (1992) Report of The Financial Aspects of Corporate Governance, London, Gee.

Charfeddine, L. dan Elmarzougui, A. (2010) "Institutional Ownership and Firm Performance: Evidence from France", IUP Journal of Behavioral Finance, 7 (4), 35-46.

Chung, K. H. and Pruitt, S. W. (1994) "A Simple Approximation of Tobin's Q", Financial Management, 23 (3), 70-74.

Cinantya G. A. A. P. dan Merkusiwati K. L. A. (2015) "Pengaruh Corporate Governance, Financial Indicators, dan Ukuran Perusahaan pada Financial distress", E-Jurnal Akuntansi Universitas Udayana, 10 (3), 897-915. 
Darmawan, S. (2016) "Analisis Pengaruh Corporate Governance, Variabel Ekonomi Makro Terhadap Financial Distress Dengan Variabel Kontrol Ukuran Perusahaan dan Jenis Kepemilikan”, 7 (1), 100-122.

Elhikioya, B.I. (2009) "Corporate Governance Structure and Firm Performance in Developing Economies: Evidence From Nigeria", Corporate Governance: International Journal of Business in Society, 9 (3), 231-243.

Fama, E.F. and French, K.R. (1992) "The Cross-section of Expected Stock Returns", The Journal of Finance, 47 (2), 427- 465

Gitman, L. J. and Zutter, C. J. (2015) Principle of Managerial Finance, $14^{\text {th }}$ Edition. England: Pearson.

Hanousek, J., Kocenda, E., dan Svejnar, J. (2007) "Origin and Concentration. Corporate Ownership, Control and Performance in Firms After Privatization", Economics of Transition, 15 (1), 1-31.

Hussain, F., Ali, I., Ullah, S. dan Ali, M. (2014) "Can Altman Z-score Model Predict Business failures in Pakistan?, Evidence from Textile companies of Pakistan", Journal of Economics and Sustainable Development, 5 (13), 110-115.

Ismail, R. (2016) "Impact of Liquidity Management on Profitability of Pakistani Firms: A Case of KSE-100 Index", International Journal of Innovation and Applied Studies, 14 (2), 304-314.

Jensen, M. dan Meckling, W. (1976) Theory of The Firm: Managerial Behaviour, Agency Costs and Ownership Structure", Journal of Financial Economics, 3 (4), 305-360.

Khaliq, A, Basheer Hussein, M, A., Hassanudin Mohd T.T, Md Yousuf H., dan Nurun N. (2014) "Identifying Financial Distress Firms: A Case Study of Malaysia's Government Linked Companies (GLC)", International Journal of Economics, Finance, and Management, 3 (3), 141-150.

Klapper, L. F., \& Love, I. (2002) Corporate Governance, Investor Protection, and Performance in Emerging Markets. World Bank Working Paper.

Laurenzia, C. dan Sufiati (2015) "Pengaruh Kepemilikan Institusional, Ukuran Dewan Komisaris, Likuiditas, Aktivitas, dan Leverage Terhadap Financial Distress Perusahaan Manufaktur yang Terdaftar di BEI Periode 2013-2014", Jurnal Ekonomi, 20 (1), 72-88.

Li, H.X., Wang, Z.J. and Deng, X.L. (2008) “Ownership, Independent Directors, Agency Costs and Financial Distress: Evidence From Chinese Listed Companies", Corporate Governance: The International Journal of Business in Society, 8 (5), 622-636.

Margaretha. Farah (2016) Manajemen Keuangan untuk Manajer Non Keuangan, Cetakan ke4, Jakarta, Penerbit Erlangga.

Martono, C. (2002) "Analisis Pengaruh Profitabilitas Industri, Rasio Leverage Keuangan Tertimbang dan Intensitas Modal Tertimbang Serta Pangsa Pasar Terhadap ROA dan ROE Perusahaan Manufaktur yang Go-public di Indonesia“, Jurnal Akuntansi \& Keuangan, 4 (2), 126 - 140.

Noviandri, T. (2014) "Peranan Analisis Rasio Keuangan dalam Memprediksi Kondisi Financial Distress Perusahaan Sektor Perdagangan”, Jurnal Ilmu Manajemen, 2 (4), 1655-1665.

Parker, S., Peters, G.F. and Turetsky, H.F. (2002) "Corporate Governance and Corporate Failure: A Survival Analysis", Corporate Governance: International Journal of Business in Society, 2 (2), 4-12. 
Pourali, M. R, Samadi M. and Karkani E. (2013) "The Study of Relationship Between Capital Intensity and Financial Leverage with Degree of Financial Distress in Companies Listed in Tehran Stock Exchange" International Research Journal of Applied and Basic Sciences, 4 (12), 3830-3839.

Putri, N.W.K.A. dan Merkusiwati, N.K.L.A (2014) "Pengaruh Mekanisme Corporate Governance, Likuiditas, Leverage, dan Ukuran Perusahaaan Pada Financial Distress", E-Jurnal Akuntansi Universitas Udayana, 7 (1), 93-106.

Shahwan. T. M. (2015) "The Effects of Corporate Governance on Financial Performance and Financial Distress: Evidence From Egypt", Corporate Governance, 15 (5), 641662.

Syari, D. W. (2014) "Pengaruh Likuiditas dan Leverage terhadap Kinerja Keuangan Perusahaan Rokok di Bursa Efek Indonesia" Jurnal Ilmu \& Riset Manajemen, 3 (3), $1-18$.

Talebria, G., Mahdi S., Hashem V. and Shahram S. (2010) "Empirical Study of the Relationship between Ownership Structure and Firm Performance: Some Evidence of Listed Companies in Tehran Stock Exchange", Journal of Sustainable Development, 3 (2), 264-270.

Vassalaou, M. dan Xing, Y. (2004) "Default Risk in Equity Returns", The Journal of Finance, LIX (2), 831-868.

Wang, Z.J. and Deng, X.L. (2006) "Corporate Governance and Financial Distress: Evidence From Chinese Listed Companies", The Chinese Economy, 39 (5), 5-27.

Wardhani, R. (2007) "Mekanisme Corporate Governance dalam Perusahaan yang Mengalami Permasalahan Keuangan”, Jurnal Akuntansi dan Keuangan Indonesia, 4 (1), 95-114.

Windah, G. C. dan Andono, F. A (2013) "Pengaruh Penerapan Corporate Governance Terhadap Kinerja Keuangan Perusahaan Hasil Survei IICG Periode 2008-2011”, Jurnal Ilmiah Mahasiswa Universitas Surabaya, 2 (1), 1-20.

Widyasaputri, E. (2012) "Analisis Mekanisme Corporate Governance pada Perusahaan yang Mengalami Kondisi Financial Distress", Accounting Analysis Journal, 1 (2), 18.

Wright, P., Mark K., Ananda M. and Michael L. P. (2009) "Do the Contingencies of External Monitoring, Ownership Incentives, or Free Cash Flow Explain Opposing Firm Performance Expectations?", Journal Management Governance, 13: 215-243.

Yuniarta, G. A., Ambarwati N, S. dan Sinarwati N. K. (2015) "Pengaruh Modal Kerja, Likuiditas, Aktivitas, dan Ukuran Perusahaan Terhadap Profitabilitas" E-Journal Akuntansi Universitas Pendidikan Ganesha, 3 (1). 